NOTICE: This is the author's version of a work that was accepted for publication in Cities. Changes resulting from the publishing process, such as peer review, editing, corrections, structural formatting, and other quality control mechanisms may not be reflected in this document. Changes may have been made to this work since it was submitted for publication. A definitive version was subsequently published in Cities [27, 4, 2010] DOI 10.1016/j.cities.2009.12.005 


\title{
The rhetoric of adaptive reuse or reality of demolition: Views from the field
}

\begin{abstract}
The City of Perth in Western Australia is a relatively modern city and was founded in 1829. A considerable amount of its built stock will become redundant in the near future. An issue that will face many building owners, designers, property developers and planners will be to adapt or demolish existing buildings to meet changing economic and social needs and issues related to sustainability. The rhetoric associated with the benefits of adaptive re-use has been widely espoused. It would appear in reality; however, that owners and practitioners are only embracing this sustainability strategy in a piecemeal manner within Perth. This paper examines owners and practitioners' views and experiences associated with adaptive re-use. In conjunction with the normative literature and the research findings, a building viability process model is presented that can be used by owners, occupiers and planners to determine the strategy needed to meet changing commercial and regulatory demands being required of buildings.
\end{abstract}

Keywords: Adaptive re-use, demolition, commercial building, decision-making, Perth, Western Australia

\section{INTRODUCTION}

As buildings appreciate in years their operational and commercial performance decreases until eventually they fall below the expectations of owners and occupiers (Hakkinen, 2007). Apart from the natural depreciation of fabric and systems, the effectiveness of buildings is impacted by constantly changing market demands (Petersdorff et al., 2006). The resultant declining commercial and operating performance is a critical issue that owners and operators have to deal with throughout the lifecycles of their buildings. Responding to declining performance has resulted in decisions to purely demolish and redevelop buildings based on economic grounds (Pearce, 2004). The decision to demolish may be premature if it ignores the residual utility and value of buildings that could be optimized by adapting and refurbishing using the process of adaptive reuse (Ellison et al., 2007). Failing to optimize buildings can result in their residual lifecycle expectancy not being fully exploited, which is not a sustainable use of built stock. 
Adaptive reuse has been identified as a process to ameliorate the financial, environmental and social performance of buildings (Langston et al., 2007; Bullen, 2007). It is best described as "a process that changes a disused or ineffective item into a new item that can be used for a different purpose" (Department of Environment and Heritage, 2004). Thus, the adoption of this process for buildings can contribute to sustainability and climate change through mitigation of $\mathrm{CO}_{2}$ emissions (Bullen, 2007). This can occur through re-using the functionality of the building, components, materials and recycled materials and therefore reduce the amount of embodied energy ${ }^{1}$ needed to suit the purpose of facility that is required.

There is a growing acceptance that a process of adaptive reuse can be used as a responsive strategy that can attend to the changing needs of owners and occupiers (Wilkinson et al., 2008). A key decision that many owners and occupiers are confronted with is whether to adapt and re-use their building or demolish. Itard and Klunder (2007), for example, have suggested that the longevity of buildings can be detrimental because of their negative environmental impact, and the relative technical problems associated with renovating and refurbishing. According to Ellison et al. (2007) refurbishing a building to meet the standards needed to make a contribution to sustainability may be $12 \%$ more expensive than a standard reuse project. In a similar vein Kohler and Yang (2007) proffer that the costs of reusing buildings are lower than the costs of demolition. According to Thomson and Van der Flier (2006) an adaptive reuse strategy is only preferable to demolition if the objectives of environmental sustainability and reduced energy consumption can be attained. Building owners and practitioners, however, have been reluctant to embrace adaptive re-use because of the perceived problems associated with health and safety, increased maintenance, increased rental returns that may be required, inefficiencies in building layout and the commercial risk and uncertainty (Shipley et al., 2006; Remoy and van der Voodt, 2007; Kurul, 2007; Bullen, 2007).

While the rhetoric associated with the benefits of adaptive re-use has been widely espoused, it would appear in reality that owners and practitioners are only embracing this sustainability strategy in a piecemeal manner within Perth, Western Australia (WA) (Bullen, 2007). Perth is chosen as a City as a significant proportion of its existing building stock is approaching the end of its life cycle.

\footnotetext{
${ }^{1}$ Embodied energy is the energy required to extract, process and manufacture, and transport a product. It is considered over a material's life cycle from extraction to installation. $\mathrm{CO}_{2}$ emissions are generated during energy consumption and embodied $\mathrm{CO}_{2}$ is based on specific energy sources of a process. $\mathrm{CO}_{2}$ emissions leading to green house gases that cause climate change typically occur in embodied energy.
} 
Land is not as scarce as many other major cities and so demolition has been an option rather than refurbishment or renovation in the past, irrespective of the consequences on the environment. With increasing pressure to examine life cycle costs and adhere to the sustainability, adaptive re-use has come to the forefront of owners and practitioners agenda's. In contrast to studies that have examined the costs associated with adaptive re-use (e.g., Shipley et al. 2006), this paper examines owners and practitioners' views and experiences associated with adaptive re-use from a sustainability and social perspective. In conjunction with the normative literature and the research findings, a building viability process model that can be used by owners, occupiers and planners to determine the strategy needed to meet changing commercial and regulatory demands being required of buildings in Perth is presented.

\section{ADAPTIVE REUSE AND DEMOLITION}

The shift to building reuse and adaptation has become an increasing trend within the last decade (e.g., Ball, 2002; Bon and Hutchinson, 2000; Caccavelli and Gugerli, 2002; De Valence, 2004; Gallant and Blickle, 2005; Kohler, 2006; Bradley and Kohler, 2007; Van Beuren and de Jong, 2007; Wilkinson et al., 2008). In many cases, increasing the life of a building through reuse can lower material, transport and energy consumption and pollution and thus make a significant contribution to sustainability (e.g.Van der Voordt, 2004; Velthuis and Spennemann, 2007; Bullen, 2007). There is ubiquitous convergence among researchers that adaption can make a significant contribution to the sustainability of existing buildings (e.g. Brand, 1994; Pickard, 1996; Cooper, 2001; Balaras et al., 2004; Bromley et al., 2005; Kurul, 2007). There is also a growing perception that it is cheaper to convert old buildings to new uses than to demolish and rebuild (e.g. Vanegas et al., 1995; Ball, 2002; Department of Environment and Heritage, 2004; Douglas, 2002; Gregory, 2004; Pearce, 2004). Building longevity can raise many technical problems, particularly with respect to the durability of the external fabric and finishes. When the external fabric of a building begins to deteriorate this can cause significant problems when considering reuse. Ball (1999) suggests that such technical challenges require a wide range of renovation and refurbishment techniques. In many cases this involves finding innovative solutions that can be applied within the constraints imposed upon the design team and contractor (Shipley et al., 2006).

The relative costs, related benefits and constraints of reuse versus demolition and new build have received widespread debate. Hall (1998), Douglas (2006) and Kohler and Yang (2007) have proffered that the costs of reusing buildings are 
lower than the costs of demolition. It is potentially cheaper to adapt than to demolish and rebuild inasmuch as the structural components already exist, and the cost of borrowing is reduced, as contract periods are typically shorter (Shipley et al., 2006).

Buildings are generally demolished because they no longer have any value (Kohler and Yang, 2007). In most cases it is the market that sets this value, even though such an assessment may be based on incomplete information with no consideration given toward externalities. Douglas (2006) maintains that there is considerable value attached to retaining style and character and the so called 'solid build qualities of buildings'. According to Ball (2002) it is generally preferable to repair a building than replace it because the value of the location and quality of a new building is not necessarily better than the old one. In contrast, O'Donnell (2004) suggest that an adapted building will not completely match a new building in terms of performance, but the shortfall should be balanced against gains in social value.

Demolition is often selected when the life expectancy of an existing building is estimated to be less than a new alternative; despite any improvements that adaptive reuse may inject (Douglas, 2002). According to Mott Green Wall (2004) this would only justify limited investment on a short-term basis prior to disposal and redevelopment. Certainly the life cycle expectancy of the materials in an older building may well fall short of those in a new building. The age of materials will also directly affect the ongoing maintenance costs of an adapted building, which, as a result, may well be higher than those for a new building. However, adaptive reuse can offer a more efficient and effective process of dealing with buildings than demolition. This is because it is deemed to be safer as it reduces the amount of disturbance due to hazardous materials, contaminated ground and the risk of falling materials and dust. In particular, site work is also more convenient because the existing building presents a work enclosure that reduces downtime from inclement weather. In a similar vein, Itard and Klunder (2007) have stated that demolition should be regarded as being an environmentally unfriendly process. They found from a renovation study that adapting buildings for a new use generates less waste, uses fewer materials and probably uses less energy than demolition and rebuilding. Evidence clearly suggests that the opportunities created by adaptive reuse outweigh those presented by demolition and rebuilding (e.g., Ball, 1999; Brand, 1994; Cooper 2001; Douglas, 2002; Kohler and Hassler, 2002; Petersen, 2002). 


\section{Adaptive Re-use and Heritage Planning}

\section{RESEARCH METHODOLOGY}

The decision-making processes associated with the planning, design and construction of a building are diverse and dynamic. To gain an understanding of the issues that owners and practitioners are confronted with when considering adaptive re-use and issues pertaining to sustainability, an interpretative research approach was adopted. This was because such an approach can capture information about the beliefs, actions, and experiences of stakeholders involved in the decision-making process surrounding adaptive reuse (Doolin, 1996; Loosemore, 1999). Moreover, in considering the viability of adaptive reuse, it is necessary to consider the 'context' of the project in terms of its impact on social and natural environments as well as those of an economic nature.

\section{Interviews}

Interviews were chosen as the primary data collection mechanism as they are an effective tool for learning about matters that cannot be directly observed (Taylor and Bogdan, 1998; Patton, 1990; Silverman, 2000). The general themes that the interviewer focused on were:

- effectiveness of adaptive re-use as a strategy to achieve sustainability;

- attributes that make a building suitable or unsuitable for adaptive re-use;

- impact of adaptive re-use on stakeholders; and

- circumstances in which adaptive re-use or demolition are considered.

Eighty-one in-depth interviews were conducted over a six month period with a variety of stakeholders such as architects, developers, planners, building managers/owners and property consultants (Table 1). Interviewees were chosen for their ability to contribute towards this study through both tacit and explicit knowledge of adaptive re-use. Individual representatives from firms from the metropolitan area of Perth were selected from the Yellow Pages ${ }^{\circledR}$ using the technique of stratified random sampling and invited to participate in the research. The interviews were conducted at the offices of interviewees. Interviews were digitally recorded and transcribed verbatim to allow for the nuances in the interview to be apparent in the text. 
$<$ Insert Table 1. Characteristics of interviewees >

The interviewees' details were coded to allow for anonymity, although all interviewees were aware that it might be possible to identify them from the content of the text. The format of the interviews was kept as consistent as possible following the themes identified above. The nature of the questions allowed for avenues of interest to be pursued as they arose without introducing bias in the response. Notes were taken during the interview to support the digital recording to maintain validity. Each of the interviews varied in length from 30 minutes to two hours. Interviews were open to stimulate conversation and breakdown any barriers that may have existed between the interviewer and interviewee.

\section{Data Analysis}

Content analysis was used as the primary analysis technique on the collected data. (Krippendorf, 1980). The text derived from the interviews was analyzed using QSR Nvivo (which is a version of NUD*IST and combines the efficient management of Non-numerical Unstructured Data with powerful processes of Indexing and Theorizing) and enabled the development of themes to be identified. Using Nvivo enabled the researchers to develop an organic approach to coding as it enabled triggers or categories of interest in the text to be coded and used to keep track of emerging and developing ideas (Kvale, 1996). These codings can be modified, integrated or migrated as the analysis progresses and the generation of reports, using Boolean search, facilitates the recognition of conflicts and contradictions. This process enabled the identification of key themes during the adaptive re-use or demolition decision-making process to be identified.

\section{Research Findings}

There was general consensus amongst interviewees that buildings were unique systems as their design, construction, functionality (particularly in the use of space) and ownership would generate dissimilar outcomes. There were however a diverse ranges views with regard to the importance of variables that were propagated from the analysis. In Table 2 the influence of variables weighting from interviewees for each group is presented.

Insert Table 2. Interviewees views: Influence of variables about adaptive re-use 
In examining the feasibility of each option that stakeholders are confronted with, the decision process should be tailored to fit the circumstances of the building. For example, a property consultant stated that it was:

"Difficult to compare retaining an old building with demolishing and building a new one because the differences between the two are too great and you are not comparing similar space”.

Respondents, particularly building managers and planners considered that several B, C, and D grade commercial buildings within Perth's Central Business District (CBD) should be demolished because they are operationally inefficient and costly to maintain. For example a planning consultant stated:

"Sometimes it may be easier to demolish and start from scratch because you can then incorporate modern heating and cooling and design features that save energy.”

Practitioners considered that such buildings could be difficult to modify or reconfigure to meet the required occupational health and safety (OHS) standards and those outlined in the Building Code of Australia (BCA) for environmental performance. Though, an architect did suggest demolition could be avoided in many instances for office buildings if internal walls were changed to accommodate a new use.

\section{Commercial Performance}

It emerged from the interviews that the commercial performance of buildings is measured by their costs in use and employee productivity. For example, a property developer made the following comment:

"In terms of construction anything is possible but commercial viability of adaptive reuse is the determining factor. This will include the cost of adapting and the sustainability of the building in its modified form."

Within those broad parameters, respondents identified a diverse set of issues that organisations need to consider when comparing the option to demolish or reuse a building. These included the ability to attract tenants, investment returns, meeting employee needs, marketability, maintenance and repair costs, operating costs, productivity levels, employee retention rates and market value. In considering demolition or reuse most organizations evaluated current and future forecasts of 
performance against one another. Such an evaluation would include the likelihood of the building meeting the basic needs of the organisation for spatial, human resource and operational requirements. Consideration for using adaptive re-use focused upon financial savings (i.e. reduced maintenance and running costs) and reducing productivity loses that could result from relocation. Conversely, it was revealed that the key issues influencing practitioners' decision-making to demolish rested upon the buildings long term operational costs and requirements. The adaptive re-use/demolition decision-making process can be complicated and include an array of variables. Fundamentally, however, owners or developers need to consider market conditions by examining the demand for a potentially re-usable building. Acknowledging this one property developer stated:

"Companies have to consider whether the building can be turned into something that is worthy of their image and if so what is the cost of that".

Similarly, an architect placed increasing emphasis on how buildings should marry with a firm's corporate culture and the way in which people worked:

"At the top end of the market they are actually looking for buildings to meet with their corporate culture and not necessarily looking for criteria that have been used traditionally".

Having a building that displays and showcases innovation as well encourages efficiency in the workplace were criteria identified by several architects.

\section{Comparative Considerations of Building Demand and Function}

The analysis of the interviews revealed four common options that should be considered as part of the adaptive reuse process: (1) relocating to a different existing building, (2) relocating to a new purpose-built building, (3) demolishing the current building and constructing a new one, (4) carrying out adaptive reuse of the current building. Any assessment should estimate the costs, viability, soundness, feasibility and advantages and disadvantages of each option. However, there are very limited examples that practitioners in Perth (WA) can refer to for the purposes of adaptive re-use decision-making. A building manager highlighted the importance of comparisons as a reference point for learning and achieving sustainable outcomes. It was stated: 
"It would be very useful to study reused buildings, particularly in providing examples that could be referred to in the future of strategies that work and those that are less successful in achieving sustainability”.

When comparing building options, respondents suggested that a balance between economic, environmental and social outcomes needed to be included in an assessment. Inclusion of only economic objectives would inexorably lead to demolition or redevelopment of the building. Similarly, a focus on purely social needs such as the retention of community, heritage and cultural amenity could lead to an uneconomical building.

If a building had some form of cultural or heritage value to the community there could be a case for owners to be offered an incentive to carry out adaptive reuse and eschew demolition and redevelopment. There was consensus among owners and practitioners that not all buildings are suitable for reuse. If buildings are physically or technically incapable of being converted, then they should be demolished. However, wholesale demolition is not a viable option in Perth, as there is insufficient capacity to immediately demolish and rebuild stock. In fact, adaptive reuse remains the only option for many buildings. For example, a town planner with a local authority planning department stated:

"Some of our old building stock is only fit for tearing down and replacing it with something of a high standard, particularly as now we can encourage building something that can be adapted in the future."

\section{Cost Factors of Reuse}

Cost is a major factor that is taken into account when considering adaptive reuse or demolition. Serendipitously, it was revealed that a vast majority of respondents placed cost on a par with the benefits of sustainable outcomes. In addition, the need for ameliorated tools and techniques for whole-life cycle costing were deemed necessary to effectively deliver sustainable outcomes. When examining an array of building options the building condition, scope of refit, overall cost saving, value of the building and land should be all considered for the purposes of a cost-benefit analysis. This was emphasised by a property developer who stated:

"It will only work if the bottom line is fully measured i.e. that all the costs and benefits are factored in over the projected lifecycle of the building. This includes the cost of taking the demolished building to the tip”. 
Adaptive reuse may not be an economically viable option when the structure of a building requires extensive strengthening to be undertaken. Several architects suggested that buildings reach a point in their life where they cannot be adapted anymore and demolition is the only solution. In fact, an example of a commercial office building that was in excess of 100 years old was provided where adaptive reuse had been undertaken regardless of the practical, technical and commercial reasons. The issue in this instance pertained to the on-going maintenance costs. The owner had simply taken a short term view to address the demand for office space within the Perth CBD which had arisen because of the resources boom. An architect suggested that the complexity of a building often dictated whether it should be demolished because more often than not, with older buildings, reuse required comprehensive and difficult alterations.

\section{Risks Associated with Reuse}

A number of risks can arise during construction and on-going maintenance periods when a building has been reused. Such risks relate to the modification of the building (e.g., latent defects, hazardous materials, unstable structure), marketing or leasing (e.g., attracting tenants), and meeting the requirements of BCA. It was perceived that because of a lack of recorded information about the physical attributes and components of buildings, developers have been unaware of the extent of hazardous materials contained within them. When buildings were demolished in Perth (WA), which was once a regular occurrence within the CBD, sites were often contaminated. Accordingly this led a developer to state:

“A lot of developers haven't been aware of hazardous materials, and realised how much work may be involved with decontaminating the site”.

Once a building has been subjected to reuse there is no guarantee it will attract investors or tenants even if it meets environmental performance standards and utilises modern technologies effectively. An issue in this instance could be the buildings external and internal aesthetics, its modified layout, or its fitness for purpose. This issue was raised by an architect who suggested:

"Getting good advice about what the building could be used for, and providing some vision is important. Although there is a certain amount of risk attached to reusing a building particularly if it turns out to be unsuitable for purpose”.

\section{Operational Attributes}


The operational attributes of existing buildings was identified as key criteria for comparing adaptive reuse with demolition. Irrespective of design aesthetics, building functionality juxtaposed with operational efficiency were identified as critical factors that would determine if a reused building is a success or failure over its life time. Operational attributes involve the ability of a building to perform efficiently in terms of meeting specified benchmarks (e.g., energy consumption, resource usage, costs in use, repairs and maintenance). For example, a building manager stated:

"Feasibility studies should determine the extent to which adaptations could be effective and whether projected outcomes meet certain sustainability benchmarks (e.g. energy efficiency)".

Energy efficiency was identified by all interviewees as an issue with many existing buildings in Perth. Of concern for a developer was whether adaptive reuse would make a building more energy efficient, and what the difference between the on-going energy costs for an existing building would be compared to the total cost of adapting a project. In this instance, cost appeared to be the determining factor for considering adaptive reuse. In contrast, owners suggested that the success of adapting a building was dependent upon it being able to meet current and future demands of possible internal reorganisations. Several owners revealed that internal changes were often needed to accommodate additional staff, new technology or a change in functionality of space.

\section{Suitability of Buildings to Undertake Adaptive Reuse}

The physical attributes of a building were found to be a factor that influenced the decision to undertake adaptive reuse. Considerations that needed to be taken into account are dimensional characteristics (e.g. physical footprint, dimensional flexibility, size of floor plate), aesthetic appeal and building type. Additionally, it was revealed that the technical difficulty of conversion, particularly the inclusion of new services and equipment were issues that needed to be examined in detail.

From the interviewees' comments, it was perceived that a building's suitability for reuse in Perth is influenced by the era within which it was constructed. For example, buildings generally constructed in the 1960's and 1970's were considered to have minimal suitability because of their poor quality of construction. One particular building manager stated that: 
"Most buildings offer opportunities for reuse but those built to minimum space standards and quality such as many 60's buildings would probably be less suitable for reuse".

Buildings designed for a specific purpose (e.g., telephone exchanges, sport centres, and wool storage warehouses) are arduous to retain and adapt without significant expenditure. Low rise buildings that did not fully utilize the available plot ratio or zoning were deemed to be an uneconomical proposition for reuse and thus it would be more effective to demolish and replace them with a high rise building. Unless a building had some redeeming architectural features or was heritage listed, adaptive reuse would generally be uneconomic and could not be justified in terms of sustainability. For example, an architect considered several buildings constructed in Perth in the 1970s to be dysfunctional and stated:

"Generally, old buildings particularly those from the 70s are just not equipped to deliver what is required in terms of natural light and have cramped conditions.”

\section{Sustainability Performance}

There was general consensus among owners and practitioners that commercial buildings needed to reduce their energy usage, water consumption and $\mathrm{CO}_{2}$ emissions. In particular, town planners implied that existing buildings have had a significant impact on communities, social and visual amenity, and social equity within the CBD and surrounding office developments in suburbs such as East and West Perth and Subiaco. It was also emphasised that if buildings were going to be subjected to reuse, then societal shifts needed to be taken into account. For example, if a building was converted to offices, how readily could be it adapted in the future to meet possible demands for housing? Despite environmental and social sustainability improvements that can be integrated within an adaptive reuse project, cost was deemed to be the keystone that would influence sustainability performance. Shipley et al. (2006) has also been identified this point.

The measurement and evaluation of sustainability performance was identified as a problematic issue for interviewees. Architects and building managers suggested that too much reliance was being placed on the Green Star environment rating system or National Australian Built Environment Rating System (NABERS) by owners and users. Improvements carried out during adaptive reuse were considered to provide the opportunity to link the performance of a building directly to the objectives of sustainability (e.g., reusing and recycling materials, 
reducing resource and energy consumption, emissions and waste generation). If more buildings could be reused and demolition was minimised, then a positive contribution to sustainability may be achieved. For example, a property consultant stated:

"Reuse also reduces the amount of waste created and energy and resources
consumed in constructing new buildings, which contributes to
sustainability."

From the findings presented it can be seen that the decision process associated with adaptive reuse or demolition can be a bewildering process for owners and practitioners. The City of Perth is a relatively modern city when compared to other regional and capital cities around the world. A significant amount of built stock, however, is coming to the end of its usable life, and therefore many owners will be confronted in due course with the decision to either reuse or demolish their buildings. A plethora of new commercial buildings have been constructed in the CBD over the last ten years to meet the increasing demand for office space, though according to interviewees consideration for the future adaption of such buildings has not been given the attention it deserved. A number of five and six star buildings in accordance with Greenstar are currently being constructed in Perth with limited attention being given toward their future adaptive re-use. In addressing the future needs of stakeholders, a building viability process model is developed and presented hereinafter.

\section{BUILDING VIABILITY DECISION-MAKING}

A primary reason for the disposal of a building is because it does not meet the immediate needs of owners and their occupiers. Several factors derived from the analysis influences the decision-making process and are presented in Figure 1. The factors are referred to as 'states' in Figure 1 and relate to the conditions of declining commercial and operating performance of a building. Such states predominantly influence a response to decide to discontinue with the building.

$<$ Insert Figure 1. Building life viability decision-making process >

The research findings indicated that building owners and occupiers had different opinions with regard to their response to the influencing states imposed upon them. Once a building was considered no longer viable, building owners preferred to either carry out adaptive reuse or demolish, where occupiers had a preference to relocate or return to the building after it had been subjected to conversion. The analysis revealed that building owners placed increasing emphasis on commercial 
performance, whereas occupiers and users focus on outcomes related to operating performance and productivity. When performance requirements are not being met the usefulness of the building is given due consideration and action is taken to decide whether to reuse, dispose or relocate.

Commercial performance should not be the only criteria that are used to determine usefulness of a building. Cantacuzino (1989) has identified a number of reasons why building owners should consider a building to be no longer useful. These include:

- $\quad$ reaching the end of their service life;

- $\quad$ reduction of their usefulness over time;

- $\quad$ becoming out of fashion and out of date;

- deterioration of the fabric or structure;

- reduction in efficiency coupled with increased expenditure to keep the building operating;

- $\quad$ reduction in ability to meet the demands of occupants over time;

- population movements either increasing or decreasing; and

- prolonged vacancy rates.

User needs and social equity are often excluded from the decision-making process when considering the viability of a building. The need to develop a mechanism to provide integrated social, economic and environmental information for decision makers has been recognized by Steemers (2003), Lowe (2004), and Rousseau (2004). Only when buildings are treated as a reusable resource rather than a product that is consumed and discarded will a step toward achieving sustainable outcomes will be attained.

Spector (2003) states that when considering a building for adaptive reuse it is essential to examine the following issues:

- building's structural layout and its capacity to accommodate required spaces and functions;

- $\quad$ energy efficiency of the building's walls, windows, and roof;

- $\quad$ building's potential for meeting building, heath, safety, and accessibility requirements;

- condition of mechanical, plumbing, and electrical systems and their capacity for modification; 
- $\quad$ the presence of hazardous materials;

- $\quad$ ability of the building and site to provide a safe and secure environment; and

- $\quad$ convenience and safety of the building's location

It is suggested that decision-makers should initially consider a building's performance requirements rather than cost. If cost is used as the deciding criteria, then it would be inappropriate to consider the expense that would be incurred for reuse of the existing building. If a six star energy rating (Greenstar) was required for a building it would obviously cost more than a four star, but the occupiers would gain greater amenity.

Adaptive reuse decision should be based on the individual barriers and opportunities unique to each building. Any assessment of this ability should identify decisions that must be made to balance occupant needs with considerations of sustainable adaptive reuse. Sustainability is becoming more of a factor in reuse decisions, but as noted above, economic outcomes still tend to be the benchmarks that determine whether buildings are considered suitable for reuse. The extent to which adaptive optimisation links the commercial and operational performance of a building to outcomes that meet the objectives of sustainability is influenced by an array of complex criteria. These are categorised under the environmental, social, economic and governance concepts of sustainability, as noted in Figure 2. The analysis revealed that criteria are interdependent and are considered an integral part of adaptive reuse decisionmaking for owners and occupiers.

$<$ Insert Figure 2. Adaptive re-use decision-making process model >

Regardless of issues associated with sustainability, if buildings are poorly designed and constructed they will not exceed their expected economic life. Environmentally sustainable buildings are more robust, flexible and durable and therefore have a longer life (Bartlett and Howard, 2000). Yet, there are many modern buildings that should be demolished in Perth inasmuch as they have been designed with a disregard to whole life cycle costs. Moreover, many existing buildings are becoming obsolete and cannot be economically re-valued to meet contemporary requirements. They are destined for less than optimum usage, costly refurbishment, or demolition. These buildings were designed to meet previous standards of function and technology. As a result, they were so tightly engineered, optimised, and integrated to current programs of use that now they are incapable of being adjusted. 
Developers invariably link opportunities for reuse to investment outcomes. They realise the market potential that a building presents when it is in a prime location, and its aesthetic appeal to tenants or purchasers. These same features of location and design are diametrically linked to the outcomes required by building managers and owners. Yet there is a fundamental difference in the way that these variables are viewed by parties. Developers idiosyncratically aim to acquire short term investment performance, whereas building owners/managers seek long term commercial and operating performance. Similar views are held by many development consultants and planners, particularly in terms of the contribution that existing buildings can make to the stabilization of urban communities.

A critical part of the decision process for adaptive reuse is assessing the extent of upgrading required and whether adaption would sustain the viability of a building's life cycle. Adaptive reuse can enable buildings to accommodate the changes that revolve around shifting economic, environmental and social patterns. The enhancement associated with sustainability of buildings is dependent upon initiatives that seek to optimise whole life cycle costs and the social performance of buildings

\section{CONCLUSION}

The City of Perth in Western Australia is a modern and vibrant place that will be confronted with redundant built stock in years to come. An issue that will face many building owners, designers, property developers and planners will be to adapt or demolish existing buildings. Lessons can be learnt from other cities such as Los Angeles, New York, and London, but each city is unique in terms of owner and community requirements and needs. The fundamental issues that owners and practitioners are confronted with in Perth (e.g., suitability of the building, environmental performance, and costs) are not dissimilar to those experienced elsewhere in the world, but it is important to bear in mind the ways in which a building will make a positive contribution to sustainability, especially the community within which it serves and represents. Adaptive reuse is beginning to be considered amongst Perth owners and practitioners because of the economic, social and environmental benefits that can be espoused. In assisting those with their decision-making process a building viability and adaptive reuse model was propagated. However, the jury appears to be still out on whether adaptive reuse is the most appropriate strategy for meeting the changing needs and demands of developers, occupiers and owners for exiting building stock in Perth. Further 
empirical research is required to examine the role of adaptive reuse in the context of its contribution to sustainability.

Acknowledgments

\section{REFERENCES}

Balaras, C. A., E.Dascalaki, and S. Kontoyiannidis. 2004. Decision Support Software for Sustainable Building Refurbishment. ASHRAE Transactions 110(1): 592-601.

Ball, R. 1999. Developers, regeneration and sustainability issues in the reuse of vacant buildings. Building Research and Information 27(3):140-148.

Ball, R. 2002. Re-use potential and vacant industrial premises: revisiting the regeneration issue in Stoke-on-Trent. Journal of Property Research 19(2):93-110.

Bartlett, E., and N. Howard. 2000. Informing the decision makers on the cost and value of green building. Building Research and Information 28(5/6): 315324.

Bon, R., and K. Hutchinson. 2000. Sustainable construction: some economic challenges. Building Research and Information 28(5/6): 310-314.

Bradley, P.E., and N.Kohler. 2007. Methodology for the survival analysis of urban building stocks. Building Research and Information 35(5): 529-542.

Brand, S. 1994. How Buildings Learn: What Happens After They're Built. New York: Viking Penguin.

Bromley, R.D.F., A.R. Tallon, and C.J. Thomas. 2005. City Centre Regeneration through Residential Development: Contributing to Sustainability. Urban Studies, 42(13) : 2407-2429.

Bullen, P.A. 2007. Adaptive reuse and sustainability of commercial buildings, Facilities 25 (1/2) (2007), pp. 20-31.

Caccavelli, D., and H.Gugerli. 2002. TOBUS - a European diagnosis and decision-making tool for office bulding upgrading. Energy and Buildings 34(2) :113-119.

Cantacuzino, S. 1989. Re-architecture: old buildings/new uses. New York:Abbeville Press.

Cooper, I. 2001. Post-occupancy evaluation-where are you? Building Research and Information 29(2): 158-163.

Davis Langdon and Everest and Mott Green Wall. 2004. Cost Model. Building Magazine, April 16.

Department of Environment and Heritage. 2004. Adaptive Reuse. Canberra: Commonwealth of Australia. 
De Valence, G. 2004. The Construction Sector System Approach. CIB Publication No.293, CIB, Rotterdam, The Netherlands.

Doolin, B. 1996. Alternative views of case research in information systems. Australian Journal of Information Systems. 3(2): 21-29.

Douglas, J. 2002. Building Adaptation. Woburn: Butterworth-Heinemann.

Douglas, J. 2006. Building Adaptation. Oxford and Burlington, MA: Butterworth Heinemann.

Ellison, L., S.Sayce, and J.Smith. 2007. Socially Responsible Property

Investment: Quantifying the Relationship between Sustainability and Investment Property Worth. Journal of Property Research 24(3): 191-219.

Gallant, B.T., and F.W. Blickle 2005. The Building Decommissioning Assessment: A New Six-Step Process to Manage Redevelopment of Brownfields with Major Structures - Environmental Practice, 2005 Cambridge University Press

Gregory, J. 2004. New South Wales Department of Housing Rehabilitation. New

Ways for Older Housing. http://www/housing.nsw.gov.au/rehab.htm (accessed August 21, 2006).

Haakinen, T. 2007. Assessment of indicators for sustainable urban construction. Civil Engineering and Environmental Systems 24(4): 247-259.

Hall, P.G. 1998. Cities on Civilisation. London: Wiedenfeld and Nicolson.

Itard, L., and G. Klunder. 2007. Comparing environmental impacts of renovated housing stock with new construction. Building Research and Information 35(3): 252-267.

Kohler, N. 2006. A European perspective on the Pearce report: policy and research. Building Research and Information 34(3): 287-294.

Kohler, N., and U. Hassler. 2002. The building stock as a research object. Building Research and Information, 30(4): 226-236.

Kohler, N., and W.Yang. 2007. Long-term management of building stocks. Building Research and Information 35(4): 351-362.

Kurul, E. 2007. A qualitative approach to exploring adaptive re-use processes. Facilities 25(13/14): 554-570.

Kvale, S.1996. The 1000-page question. Qualitative Inquiry 2(3):275-284

Langston, C., F.K.W.Wong, E.C.M. Hui, and Li-Yin Shen. 2007. Strategic assessment of building adaptive reuse opportunities in Hong Kong, Building and Environment,

Loosemore, M. 1999. A grounded theory of construction crisis management. Construction Management and Economics 17(1): 9-19.

Lowe, R. J. 2004. Lessons from climate change: a response to the commentaries. Building Research and Information 32(1): 75-78.

O’Donnell, C. 2004. Getting serious about green dollars. Property Australia 18(4):1-2. http://www.propertyoz.com.au (Accessed September 7, 2006).

Patton, M.Q. 1990. Qualitative interviewing and research methods, $2^{\text {nd }}$. Ed.London: Sage

Pearce, A.R. 2004. Rehabilitation as a Strategy to Increase the Sustainability of 
the Built Environment. http://maven.gtri.gatech.edu/sfi/resources/pdf (Accessed September 21, 2005).

Petersdorff, C., T.Boermans, and J. Harnisch. 2006. Mitigation of CO2 emissions from the EU-15 Building Stock. Beyond the EU Directive on the Energy Performance of Buildings. Environmental Science and Pollution Research 13(5): 350-358

Petersen, E. H. 2002. $3^{\text {rd }}$ International Conference on Sustainable Building, 23-25 September, 2002: An LCA based assessment tool for the building industry. Norway: BEAT 2002.

Pickard, R. D. 1996. Conservation in the Built Environment. Essex : Addison Wesley Longman Ltd.

Remoy, H.T., and T.J.M. van der Voordt. 2007. A new life: conversion of vacant office buildings into housing. Facilities 25(3/4): 88-103.

Rousseau, D. 2004. Adapting to climate change: some observations. Building Research and Information 32(1): 58-60.

Shipley, R., S.Utz, and M. Parsons. 2006. Does Adaptive Reuse Pay? A Study of the Business of Building Renovation I Ontario, Canada. International Journal of Heritage Studies 12(6): 505-520.

Silverman, D. 2000. Doing qualitative research: a practical handbook. London: Sage.

Spector, S. 2003. Creating schools and strengthening communities through adaptive reuse. Washington: National Clearinghouse for Educational Facilities.

Steemers, K. 2003. Towards a research agenda for adapting to climate change. Building Research and Information 31(3-4): 291-301.

Taylor, S.J., and R. Bogdan.1998. Introduction to Qualitative Research Methods: The Search for Meaning. New Jersey: John Wiley and Sons Inc.

Thomsen, A., and K. van der Flier, 2006. XXXIV IAHS, World Congress on Housing, Sustainable Housing Design, September 20-23 2006: Life Cycle of Dwellings; a Conceptual Model Based on Dutch Practice. IAHS: Naples.

Van Beuren, E., and J. de Jong. 2007. Establishing sustainability: policy successes and failures. Building Research and Information 35(5): 543-556.

Van der Voordt, T. 2004. Costs and benefits of flexible workspaces; work in progress in the Netherlands. Facilities 21(13/14): 306-314.

Vanegas, J.A., J.R. DuBose, and A.R. Pearce. 1995. Symposium on Design for the Global Environment, November 2-3, 1995: Sustainable Technologies for the Building Construction Industry. Atlanta.

Velthuis, K., and D.H.R. Spennemann. 2007. The Future of Defunct Religious Buildings: Dutch Approaches to Their Adaptive Re-use. Cultural Trends 16(1): 43-66. 
Table 1. Characteristics of sample interviewees

\begin{tabular}{|l|c|}
\hline \multicolumn{1}{|c|}{ Profession } & N=81 \\
\hline Architects & 17 \\
\hline Property Developer & 11 \\
\hline Property Consultant & 10 \\
\hline Cost Consultant & 2 \\
\hline Project Manager & 2 \\
\hline Building Manager & 21 \\
\hline Planning Consultant & 8 \\
\hline Town Planner & 12 \\
\hline
\end{tabular}

\begin{tabular}{|l|c|}
\hline \multicolumn{1}{|c|}{ Type of Organisation } & N=81 \\
\hline Public Service Authority & 24 \\
\hline $\begin{array}{l}\text { Construction and Property } \\
\text { Development }\end{array}$ & 8 \\
\hline $\begin{array}{l}\text { Property Development } \\
\text { Consultants }\end{array}$ & 9 \\
\hline $\begin{array}{l}\text { Financial Planning and } \\
\text { Management }\end{array}$ & 10 \\
\hline Planning Consultants & 16 \\
\hline $\begin{array}{l}\text { Local Authority Planning } \\
\text { Department }\end{array}$ & 6 \\
\hline Tertiary Institutions & \\
\hline
\end{tabular}


Table 2. Interviewees views: Influence of variables about adaptive re-use decision-making 


\begin{tabular}{|l|c|c|c|c|c|}
\hline Variables & $\begin{array}{c}\text { Commercial } \\
\text { Performance }\end{array}$ & $\begin{array}{c}\text { Building } \\
\text { Demand and } \\
\text { Function }\end{array}$ & Costs & Risks & $\begin{array}{c}\text { Operational } \\
\text { Attributes }\end{array}$ \\
\hline Architects & High & Medium & Medium & Medium & Low \\
\hline Property Developer & High & High & High & High & Medium \\
\hline Property Consultant & High & High & High & High & Medium \\
\hline Cost Consultant & High & Medium & High & High & Medium \\
\hline Project Manager & High & Medium & High & High & Medium \\
\hline Building Manager & High & High & Medium & Medium & High \\
\hline Planning Consultant & Medium & Low & Medium & Medium & Low \\
\hline Town Planner & Medium & Low & Medium & Medium & Low \\
\hline
\end{tabular}




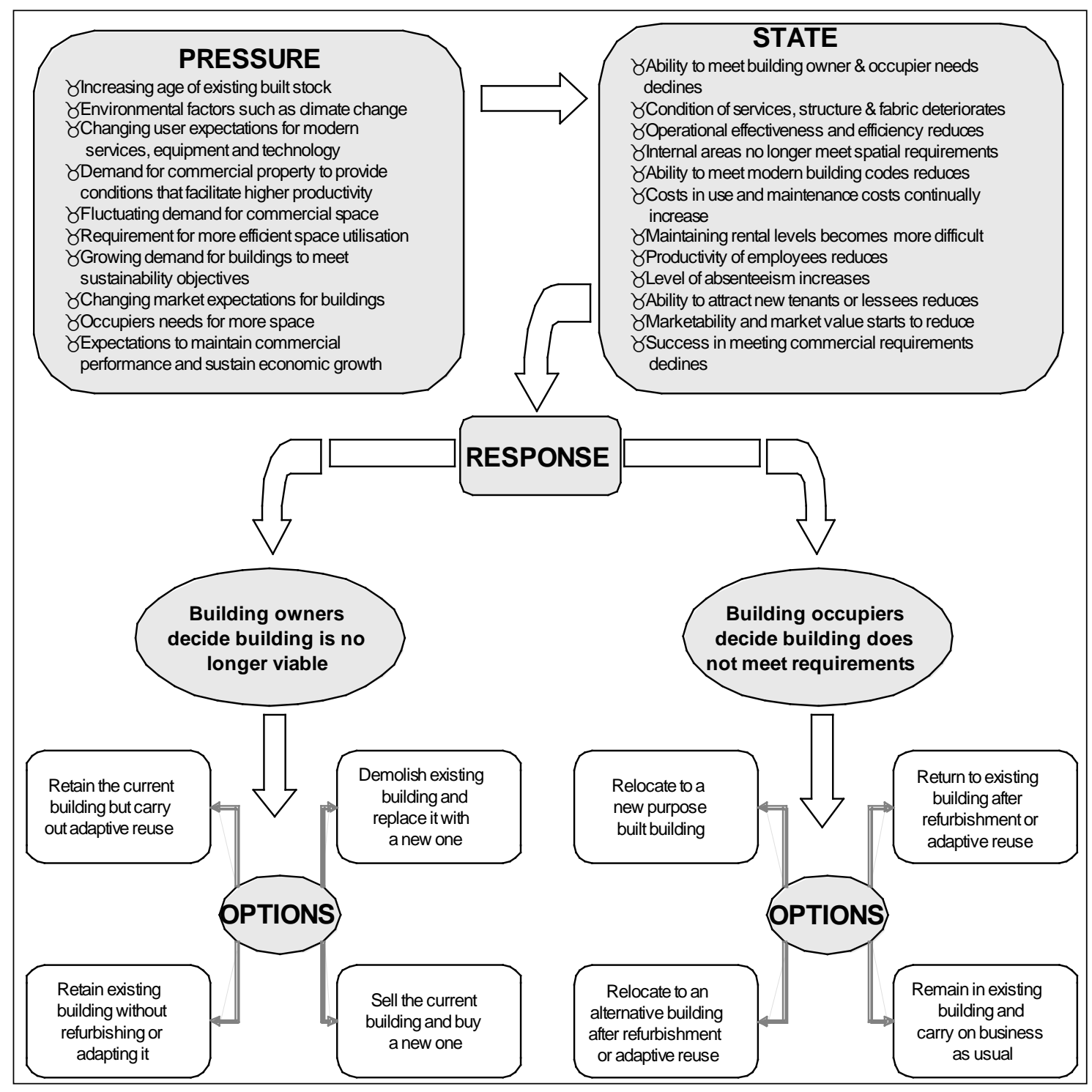

Figure 1. Building life viability decision-making process 
Treating buildings as renewable resources Reducing consumption of resources used to produce materials for new buildings Saving energy that would normally be used to produce materials for a new building Reducing emissions generated during manufacture of materials for new buildings Reducing solid waste from demolition Avoiding disturbance to adjacent properties from demolition

Avoiding construction of new building Reducing use of Greenfield sites to provide land for new buildings

Reclaiming energy originally embodied during construction of existing buildings Enabling the quality of internal environments to be improved

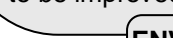
ENVIRONMENTAL
CRITERIA

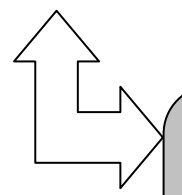

\section{ADAPTIVE REUSE} DECISION-MAKING

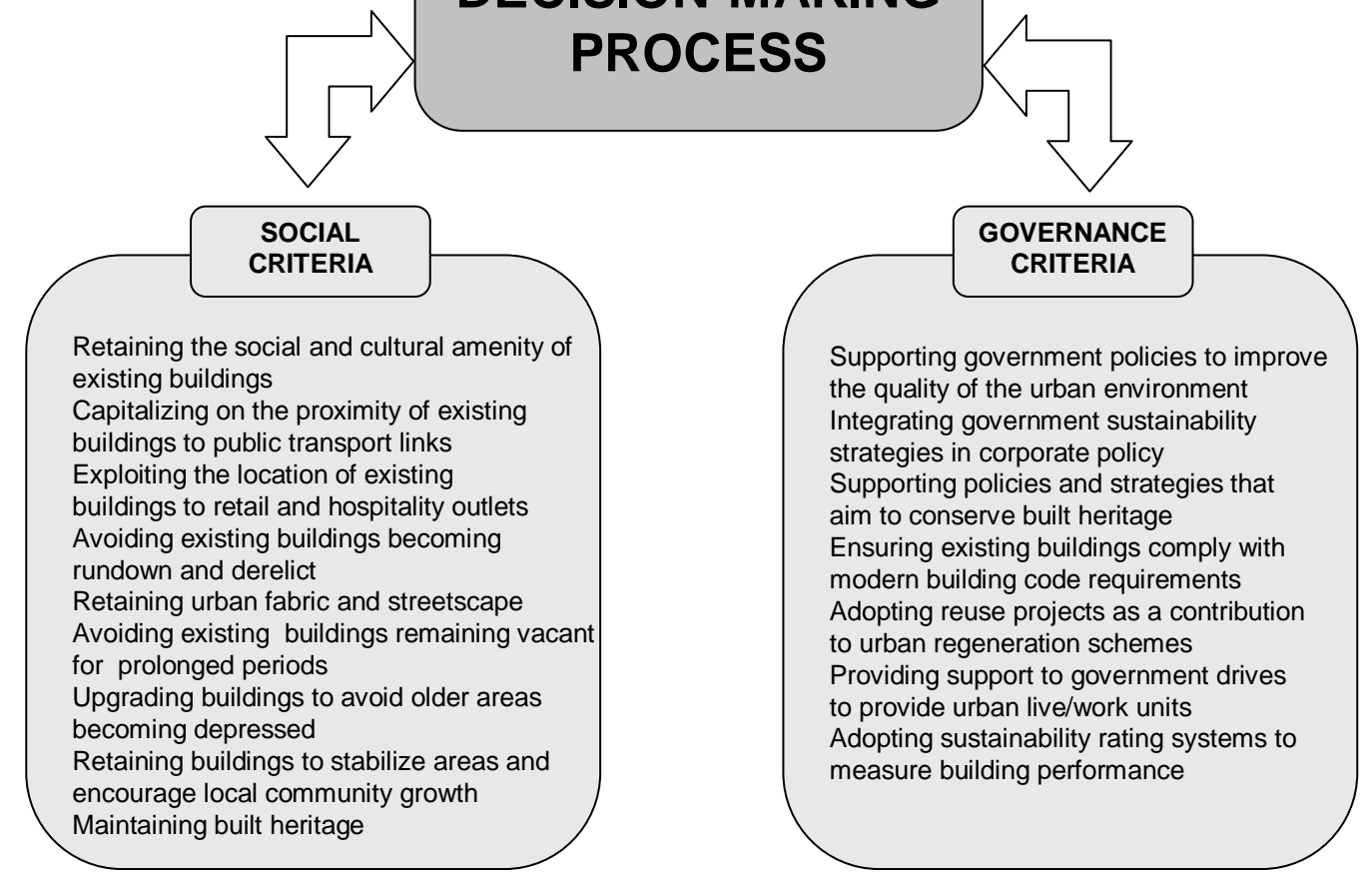

approach towards buildings Enabling improvements to the commercial performance of a building

Improving building condition so that the costs of maintenance are reduced

Adopting internal improvements to enhance the productivity of employees

Exploiting the attributes of existing buildings Enabling the market value of buildings to be maintained

Marketing the traditional features of existing buildings to attract potential tenants

Gaining commercial benefits by exploiting the value and quality of existing buildings Maintaining the commercial viability of existing buildings

Figure 2. Adaptive re-use decision-making process model 